\title{
EXPERIMENTO COM JOGOS ELETRÔNICOS NO 7ํ ANO DO FUNDAMENTAL II DA ESCOLA DUQUE DE CAXIAS ${ }^{1}$
}

\section{EXPERIMENT WITH ELECTRONIC GAMES IN THE 7th YEAR OF ELEMENTARY SCHOOL II DUQUE DE CAXIAS}

\author{
Leandro dos Santos Almeida Maia², Annelise Maymone ${ }^{3}$
}

\author{
Submetido em: 12/04/2021 \\ Aprovado em: 05/06/2021
}

e25190

\begin{abstract}
RESUMO
Este experimento com jogos eletrônicos voltados para a matemática, tem como objetivo avaliar o desempenho dos alunos do $7^{\circ}$ ano da escola Duque de Caxias. O estudo consiste em uma investigação aprofundada sobre a utilização de um jogo eletrônico criados por acadêmicos da universidade do Vale do Acaraú (IDJ) e aplicação na escola Duque de Caxias, visando a utilização desse jogo como uma nova alternativa para ser aplicada em sala de aula. Tendo como objetivo geral, analisar como o uso de jogos eletrônicos pode ser aliado ao ensino da Matemática para o desenvolvimento de uma aprendizagem efetiva e contínua. Além disso, investigar a viabilidade da utilização de um jogo eletrônico em sala de aula, aplicar o jogo RPG na escola Duque de Caxias, visando a utilização desse jogo como uma nova alternativa para ser aplicada em sala de aula, aumentar a participação e interesse por parte dos alunos, melhorar a fixação e compreensão do conteúdo abordado em sala de aula, foram nossos objetivos específicos. Foram realizadas as seguintes etapas para realização do estudo: escolha do assunto e público, escolha do tipo de jogo, desenvolvimento do jogo, escolha da escola, planejamento das atividades, aplicação e observação, coleta de dados e análise de resultados. Ao final do estudo observou-se que com a utilização dos jogos houve um aumento significativo na participação e interesse por parte dos alunos, melhorando a fixação e compreensão do conteúdo abordado em sala de aula, além de resultados extremamente satisfatórios em relação as notas finais.
\end{abstract}

PALAVRAS-CHAVES: Ensino. Matemática. Jogos. Aplicativos. Jogos Eletrônicos.

\begin{abstract}
This experiment with electronic games focused on mathematics, aims to evaluate the performance of the 7th grade students of the Duque de Caxias school. The study consists of an in-depth investigation on the use of an electronic game created by academics from the University of Vale do Acaraú (IDJ) and application at Duque de Caxias school, aiming at the use of this game as a new alternative to be applied in the classroom. Having as general objective, to analyze how the use of video games can be allied to the teaching of Mathematics for the development of an effective and continuous learning. In addition, to investigate the feasibility of using a video game in the classroom, apply the RPG game at Duque de Caxias school, aiming at the use of this game as a new alternative to be applied in the classroom, increase participation and interest on the part of students, improve the fixation and understanding of the content addressed in the classroom, were our specific objectives. The following steps were performed to perform the study: Choice of subject and public, choice of type of game, game development, school choice, planning of activities, application and observation, data collection and analysis of results.
\end{abstract}

KEYWORDS: Teaching. Mathematics. Games. Applications. Electronics Games.

\footnotetext{
1 Artigo apresentado como Avaliação Parcial para obtenção de Título Graduação em Licenciatura da Matemática pela Universidade do Vale do Acaraú.

2 Instrutor de informática, Designer Gráfico e Tecnólogo em Desenvolvimento de Softwares (FLF). E-mail: leandro26maia@hotmail.com

${ }^{3}$ Annelise Maymone é graduada em Licenciatura da Matemática (UVA) e Pós-Graduada em Docência do Ensino Superior (FVJ). E-mail: anmay@bol.com.br
} 


\section{RECIMA21 - REVISTA CIENTÍFICA MULTIDISCIPLINAR ISSN 2675-6218}

EXPERIMENTO COM JOGOS ELETRÔNICOS NO 7은 ANO DO FUNDAMENTAL II DA ESCOLA DUQUE DE CAXIAS Leandro dos Santos Almeida, Annelise Maymone

\section{INTRODUÇÃO}

Com as mudanças no mundo globalizado passamos por mudanças, e a tecnologia está inserida no dia a dia da sociedade como um todo, incluindo o professor e o aluno. $O$ avanço tecnológico reflete diretamente no objeto de interesse dos jovens atualmente. Devido a isso, o desafio do professor é buscar novas ferramentas que despertem o interesse do aluno nos dias atuais.

A evolução tecnológica trouxe novas perspectivas e ferramentas que podem ser desenvolvidas e utilizadas no processo de ensino-aprendizagem da matemática. Já passamos por um período em que, giz, lousa, compasso, ábaco e calculadora, foram inovadoras em determinado momento. Já nos dias atuais, podemos destacar os computadores, smartphones e a internet como principais recursos tecnológicos que podem ser aplicados em sala de aula, porém, ainda existe uma certa resistência por parte dos docentes que apoiam as práticas conservadoras de ensino. Podemos dizer que existe um consenso na aplicação de jogos e tecnologias em sala de aula, mas o planejamento, estrutura e acesso a informação ou capacitação ainda estão em um processo distante do ideal.

Os alunos do $7^{\circ}$ ano do ensino fundamental II possuem uma faixa etária onde é comum o uso de tecnologias e jogos no seu dia a dia. O jogo como objeto de entretenimento possui um fator motivacional enorme, pois trazem a realidade virtual de forma deslumbrante com seus gráficos e desafios.

O presente trabalho apresenta uma perspectiva sobre o uso de jogos eletrônicos e aplicativos no ambiente escolar para alunos do $7^{\circ}$ ano do fundamental II. Para isso, temos que averiguar as contribuições que os jogos eletrônicos trazem para o desempenho dos alunos no aprendizado da matemática, destacando os pontos positivos e negativos da experiência com as turmas do $7^{\circ}$ ano da escola Duque de Caxias.

\section{REVISÃO DE LITERATURA OU DESENVOLVIMENTO}

O ensino da Matemática sempre contou com tecnologias da época, tais como: Giz, apagador, lousa, régua, livro, compasso etc. O professor utilizando-se dessas ferramentas faz a demonstração do conteúdo utilizando todo o conhecimento adquirido em seu período acadêmico para resoluções de problemas como estratégia didática, com o objetivo de despertar no aluno uma motivação para que a aprendizagem ocorra. Tal procedimento caracteriza-se como uma aula tradicional utilizando os recursos tecnológicos da época. 


\title{
RECIMA21 - REVISTA CIENTÍFICA MULTIDISCIPLINAR ISSN 2675-6218
}

EXPERIMENTO COM JOGOS ELETRÔNICOS NO 7은 ANO DO FUNDAMENTAL II DA ESCOLA DUQUE DE CAXIAS Leandro dos Santos Almeida, Annelise Maymone

\begin{abstract}
Os professores agora tinham um recurso visual versátil, que era tanto livro (quando preenchido) quanto uma página em branco, ou melhor, em preto. E, o mais importante, tinham um ponto de foco, que atraia e mantinha a atenção dos alunos. $O$ quadro negro, como passou a ser chamado, ilustra e é ilustrado. Os alunos não somente ouviam o professor, mas também viam o que ele falava (Domingues, 2015).
\end{abstract}

O uso de jogos eletrônicos ou aplicativos para repetir a metodologia aplicada antes na escola é um grande desafio. O fundamental é fazer uma relação entre a aula tradicional e os jogos. Podemos utilizar os jogos para fixação do conteúdo abordado em sala de aula, pois, o desafio do jogo serve como motivação para os alunos exercitarem o conteúdo da aula.

Segundo Papert (1993) e Valente (2008), se o sujeito está intrinsecamente motivado, ele envolve-se com as atividades de forma prazerosa e essa se torna significativa. Jogos, exercícios criativos que envolvem imaginação podem desencadear o interesse e desafiar a resolução de problemas.

Já para Kenski (2007, p56-57), "A tecnologia, apesar de ser essencial à educação, muitas vezes pode levar a projetos chatos e pouco eficazes." Mas por que isso acontece? As causas são muitas. Nem sempre é por incompetência ou má vontade dos profissionais envolvidos, sobretudo professores. A análise de vários casos já relatados em pesquisas e publicações na área da educação mostra alguns problemas recorrentes, que estão na base de muitos fracassos no uso das tecnologias mais atuais na educação.

O uso de jogos matemáticos no ensino fundamental sempre foi um fator visto com bons olhos pelos professores. Porém, na prática, podemos dizer que está longe de chegar a um nível considerável devido a uma série de fatores.

Conforme Becker (2001), "Uma das principais reclamações dos professores é a dificuldade de acesso à tecnologia nas escolas. Não temos dados disponíveis sobre o número de computadores, de jogos de tabuleiro, aplicativos, projetores e de outros equipamentos por escolas. Nos EUA, com todo o investimento do governo, apesar da alta relação computador/aluno o uso de computadores para ensinar matemática é ainda baixo".

Enquanto a média nos países ricos é de cerca de um computador por estudante, no Brasil são dez alunos por equipamento. O relatório "Políticas Eficazes, Escolas de Sucesso" compara informações da oferta escolar entre os participantes da última edição do Pisa, de 2018.

A matemática é vista como uma disciplina que traz grandes dificuldades no processo ensino-aprendizagem, tanto para os alunos, como aos professores envolvidos no mesmo. A matemática desenvolve no aluno um pensamento lógico, a criatividade, dedução, indução e estimula a absorção de outras disciplinas. Podemos comparar os resultados que a matemática traz com as características que um jogo eletrônico desperta em um usuário. $\mathrm{O}$ jogo trabalha o rápido raciocínio na resolução de problemas, a criatividade, interpretação, competitividade e satisfação. Ambos, o jogo e a matemática, buscam resultados com objetivos distintos. 


\title{
RECIMA21 - REVISTA CIENTÍFICA MULTIDISCIPLINAR ISSN 2675-6218
}

EXPERIMENTO COM JOGOS ELETRÔNICOS NO 7을 ANO DO FUNDAMENTAL II DA ESCOLA DUQUE DE CAXIAS Leandro dos Santos Almeida, Annelise Maymone

\begin{abstract}
Ao analisarmos os atributos e/ou características do jogo que pudessem justificar sua inserção em situações de ensino, evidencia-se que este representa uma atividade lúdica, que envolve o desejo e o interesse do jogador pela própria ação do jogo, e mais, envolve a competição e o desafio que motivam o jogador a conhecer seus limites e suas possibilidades de superação de tais limites, na busca da vitória, adquirindo confiança e coragem para se arriscar. (Grando, 2004, p.24)
\end{abstract}

Para Vergnaud (1991), o saber se forma a partir de problemas a resolver, isto é, de situações a dominar, sendo que as concepções dos alunos são moldadas pelas situações que encontram. Logo, podemos observar na utilização de jogos que provocam importantes conflitos para a construção de conceitos ou resolução de problemas matemáticos. Nesse sentido, atribuímos um papel importante aos jogos no desenvolvimento do pensamento matemático.

A interação no processo de ensino-aprendizagem é de suma importância. A falta de interação traz uma visão contemporânea ao ensino atual, trazendo um padrão tradicional que perdura por anos. A interação com o conteúdo trabalhado através da utilização de softwares está cada vez mais presente nas escolas e, especificamente na área da matemática com os jogos eletrônicos.

A criação de Modelos Matemáticos vem ao encontro da necessidade de que se desenvolva uma técnica de acesso ao conhecimento e, tal conhecimento, acumulado e depositado, deverá ser acessível a vários níveis de necessidade. E que haja uma forma de ensino mais dinâmica, mais realista e menos formal, mesmo no ensino tradicional, permitindo atingir objetivos mais adequados a nossa realidade. (D’AMBRÓsIO, 1986, p. 25).

Entendendo os referenciais teóricos, percebemos que o tema jogos eletrônicos como recurso pedagógico poderá trazer todo dinamismo e absorção do conteúdo necessários para a fixação de conteúdos. Acreditando num bom desempenho da aprendizagem, é preciso que esses recursos sejam enfatizados, mas que também compreenda todo um projeto de capacitação educacional na formação de professores.

\section{METODOLOGIA}

A pesquisa será desenvolvida por meio de um estudo de caso onde serão descritos relatos de experiências com o jogo desenvolvido para o exercício da matemática, buscando enfatizar a experiência na escola Duque de Caxias.

\section{0 jogo como conteúdo dos PCNs}

O significado da Matemática não está relacionado apenas aos conteúdos propostos, também deve-se levar em consideração as outras disciplinas, construindo uma teia de conhecimentos que façam a conexão do que se aprende nos conteúdos em sala de aula com o 


\section{RECIMA21 - REVISTA CIENTÍFICA MULTIDISCIPLINAR ISSN 2675-6218}

EXPERIMENTO COM JOGOS ELETRÔNICOS NO 7ํ ANO DO FUNDAMENTAL II DA ESCOLA DUQUE DE CAXIAS Leandro dos Santos Almeida, Annelise Maymone

cotidiano vivenciado no seu contexto social. Os recursos didáticos serão essenciais para levar o aluno a relacionar, refletir e analisar o conhecimento. Logo, "Por meio dos jogos as crianças não apenas vivenciam situações que se repetem, mas aprendem a lidar com símbolos e a pensar por analogia (jogos simbólicos): os significados das coisas passam a ser imaginados por elas. Ao criarem essas analogias, tornam-se produtoras de linguagens, criadoras de convenções, capacitando-se para se submeterem a regras e dar explicações. (PCN/MEC, 1997, p.35) ".

Entendendo os PCNs como um referencial que orienta os profissionais da Educação para a prática escolar e na melhoria da qualidade de ensino. Acreditamos num bom desempenho da aprendizagem e no objetivo de melhorar e ampliar a educação do país. Mas, para isso, é preciso que esses recursos sejam enfatizados não só na disciplina da Matemática, mas que também compreenda todo um projeto educacional que envolva professores, a gestão escolar e os governantes.

\section{Como surgiu o jogo e a ideia de aplicar em sala de aula}

Durante o segundo semestre de 2018, foi ministrada a disciplina "PRÁTICA E VIVÊNCIA I: OFICINA E JOGOS DIDÁTICOS DA MATEMÁTICA" a uma turma de alunos do segundo semestre do curso de Licenciatura em Matemática da Universidade vale do Acaraú, na cidade de Fortaleza, Ceará, tendo por objetivo a investigação de novas tecnologias aplicadas à educação matemática; Disciplina ministrada pela professora Annelise Maymone que além de provocar a mudança de postura didática do professor incentivou a turma a utilizar ferramentas tecnológicas de apoio e ao sincronismo com o mundo atual. Durante as aulas foram abordados temas como a utilização de softwares educativos, uso de calculadoras, jogos de tabuleiro, áudio, vídeo e celulares. Assim como a elaboração, por parte dos alunos, de jogos com conteúdo didático direcionado a alunos e professores de matemática. Ao final da disciplina, todos os trabalhos seriam expostos para os docentes da faculdade.

Foi desenvolvido um jogo eletrônico para o exercício da matemática, abordando o tema porcentagem. Os resultados foram bastante satisfatórios e surge a ideia de aplicá-los em uma sala com os alunos do ensino fundamental. Daí, buscamos parcerias com professores para testar o jogo desenvolvido em outras escolas. Dentre as escolas e faculdades testadas, foram observados resultados expressivos e surpreendentes em relação ao aprendizado dos alunos. Vamos destacar a escola Duque de Caxias devido a documentação e coleta de dados que foi realizada no dia da aplicação.

\section{Local da Pesquisa}

O trabalho será realizado por meio de uma reflexão sobre a utilização de jogos eletrônicos para o exercício da matemática, mais especificamente o uso de jogos matemáticos, com turmas do $7^{\circ}$ ano do ensino fundamental II da escola Duque de Caxias, composta por alunos de classe média 


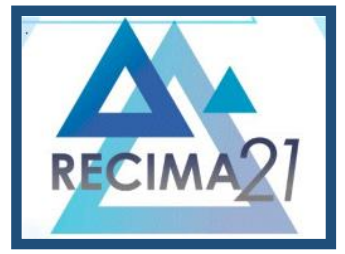

\section{RECIMA21 - REVISTA CIENTÍFICA MULTIDISCIPLINAR ISSN 2675-6218}

EXPERIMENTO COM JOGOS ELETRÔNICOS NO 7응 ANO DO FUNDAMENTAL II DA ESCOLA DUQUE DE CAXIAS Leandro dos Santos Almeida, Annelise Maymone

baixa, com poucos recursos tecnológicos, situada na Rua Perú, bairro Parangaba, Fortaleza, Ceará. A escola funciona em dois turnos e conta atualmente com 512 alunos, 10 funcionários e 18 professores.

\section{Procedimento para coleta de dados}

Os alunos da escola Duque de Caxias, especificamente, turmas $7^{0}$ ano já haviam estudados o conteúdo inserido no jogo (Porcentagem).

A professora havia preparado um questionário de revisão para ser aplicado em sala, porém, não seria utilizada as práticas tradicionais de exercitar conteúdo. Todas as questões foram abordadas com o jogo eletrônico e após a avaliação seria observado o desempenho dos alunos através de depoimento da professora e resultado de provas aplicadas sobre o conteúdo.

\section{0 jogo}

O jogo foi desenvolvido em um aplicativo chamado RPG MAKER MV, que permite que os usuários criem seus próprios jogos de RPG ${ }^{1}$. Estes jogos são similares aos populares jogos para Super Nintendo, como Zelda, Super Mário Broz, Boomber Man e Final Fantasy, a não ser que a imaginação do quem o utiliza, vá além dos recursos possíveis, criando efeitos inacreditáveis e surpreendentes, usando apenas o sistema permitido de 256 cores. No editor, você pode criar mapas, personagens e desafios. Além disso, o jogo poderá ser executado em computadores, celulares e tablets.

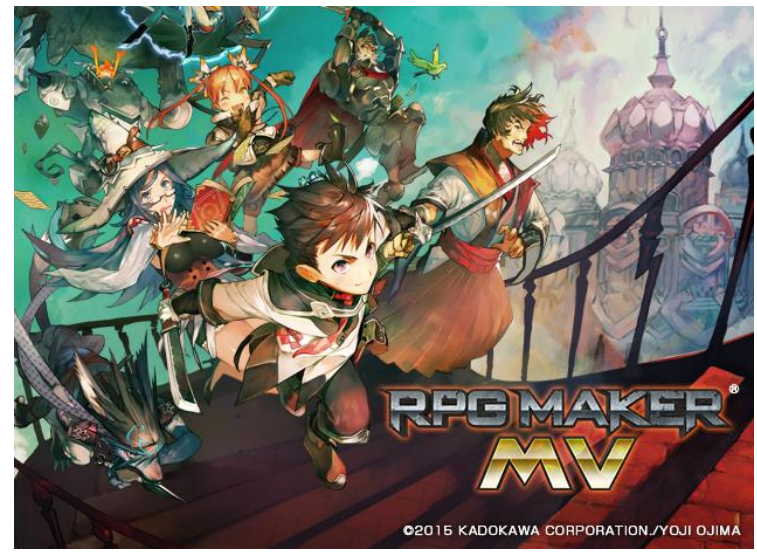

(Imagem 1: Fonte KODOKAWA CORPORATION)

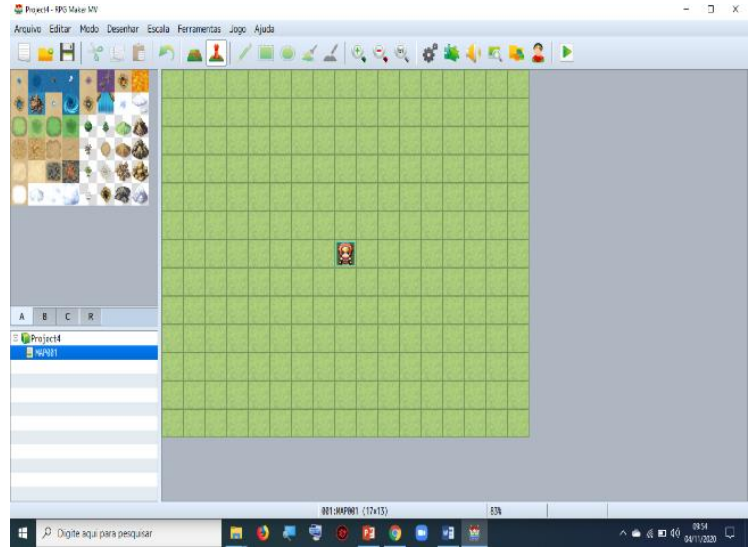

(Imagem 2: Fonte própria)

O jogo foi criado com base em uma atividade de revisão (Anexo I), onde suas questões foram aplicadas nas etapas do jogo, com o objetivo de atrair a atenção do aluno para o exercício.

\footnotetext{
${ }^{1}$ A sigla RPG nada mais é que "Role Playing Game", ou seja, um jogo onde as pessoas interpretam seus personagens e criam narrativas que giram em torno de um enredo. O RPG digital o usuário assume o papel de protagonista do jogo através de um personagem e segue um universo definido.
} 


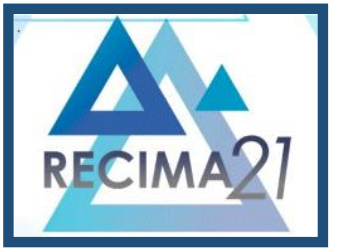

\section{RECIMA21 - REVISTA CIENTÍFICA MULTIDISCIPLINAR ISSN 2675-6218}

EXPERIMENTO COM JOGOS ELETRÔNICOS NO 7을 ANO DO FUNDAMENTAL II DA ESCOLA DUQUE DE CAXIAS Leandro dos Santos Almeida, Annelise Maymone

Denominado de "RPG - Uma nova abordagem", traz símbolos de porcentagem como plano de fundo da imagem inicial para destacar o tema.

Toda interface do jogo foi desenvolvida de acordo com o tema Porcentagem, conforme imagens abaixo, com o intuito de atrair significativamente o aluno para o jogo. $O$ mapa do jogo também foi totalmente desenvolvido com uma ideia mais contemporânea para que os alunos identifiquem a sociedade atual nos desenhos da cidade criada e relacionem ao dia a dia.

Observe nas imagens a seguir que os elementos presentes estão mostrando ao aluno ambientes da sociedade em que vivemos e a modernidade que estes acompanham diariamente. Vale ressaltar as casas, prédios, escola, padaria e farmácia como objetos de interação pois o aluno poderá visitá-los e de forma análoga poderá relacionar as ações com sua rotina.

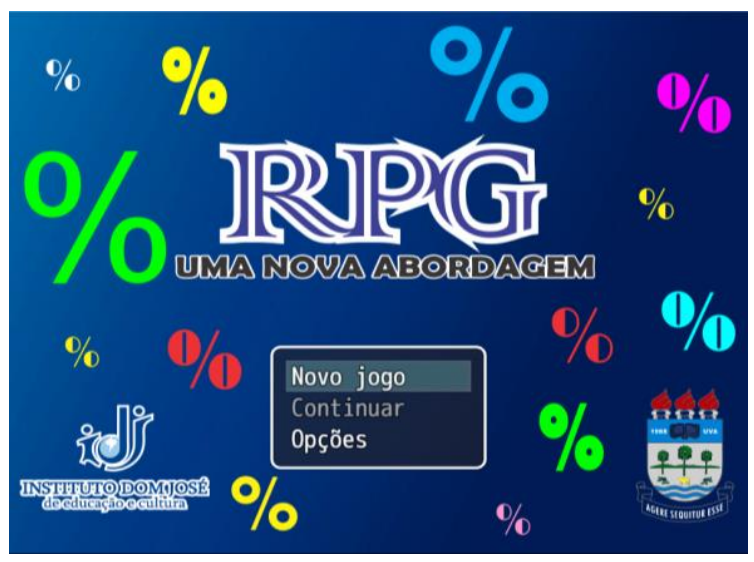

(Imagem 3: Fonte própria)

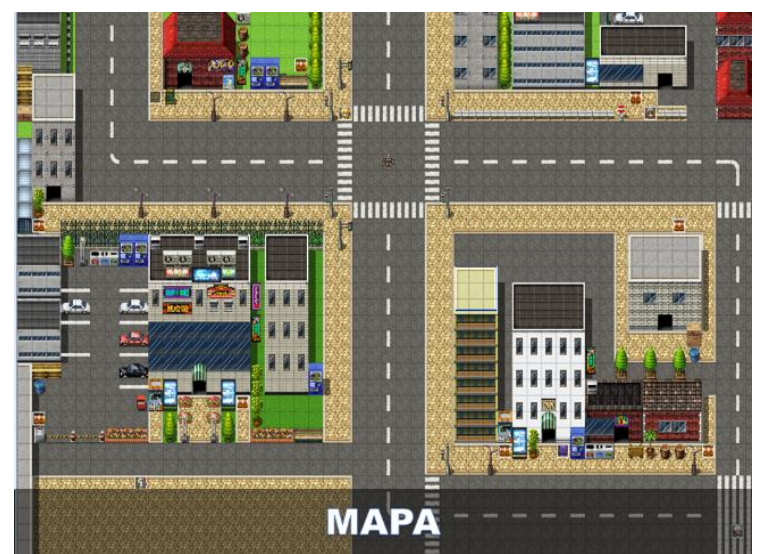

(Imagem 4: Fonte própria)

O jogo acontece em uma cidade conforme Imagem 4 e suas ações são de completa interação e simples comandos. Os alunos podem jogar no celular, onde basta clicar na tela para movimentar ou interagir com o personagem. Já no computador, o aluno poderá utilizar o mouse ou teclado, porém, também poderá utilizar um joystick se conectado ao computador. Conforme as imagens abaixo.

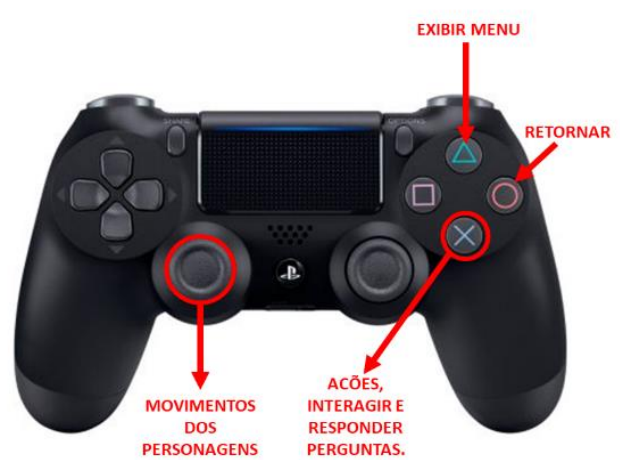

(Imagem 5: Fonte própria)

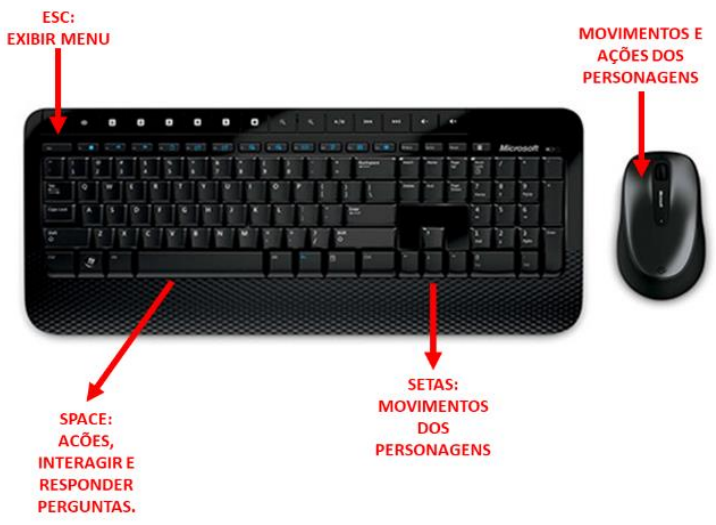

(Imagem 6: Fonte própria) 


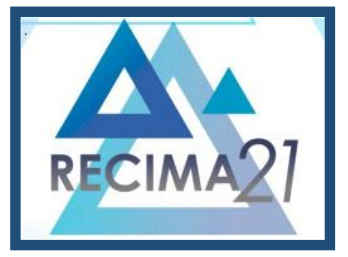

\section{RECIMA21 - REVISTA CIENTÍFICA MULTIDISCIPLINAR ISSN 2675-6218}

EXPERIMENTO COM JOGOS ELETRÔNICOS NO 7을 ANO DO FUNDAMENTAL II DA ESCOLA DUQUE DE CAXIAS Leandro dos Santos Almeida, Annelise Maymone

Os alunos deverão interagir com os personagens do jogo para resolver os desafios e ganhar pontos. As questões estão inseridas no jogo conforme imagens a seguir.

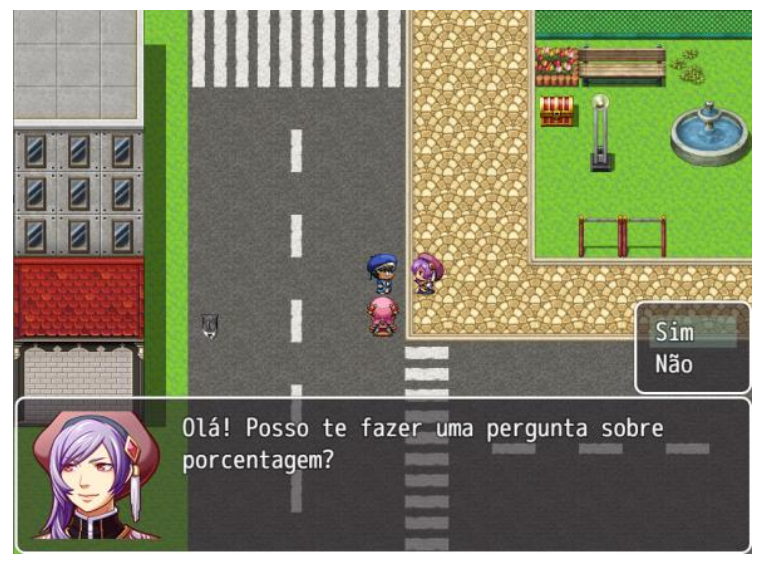

(Imagem 7: Fonte própria)

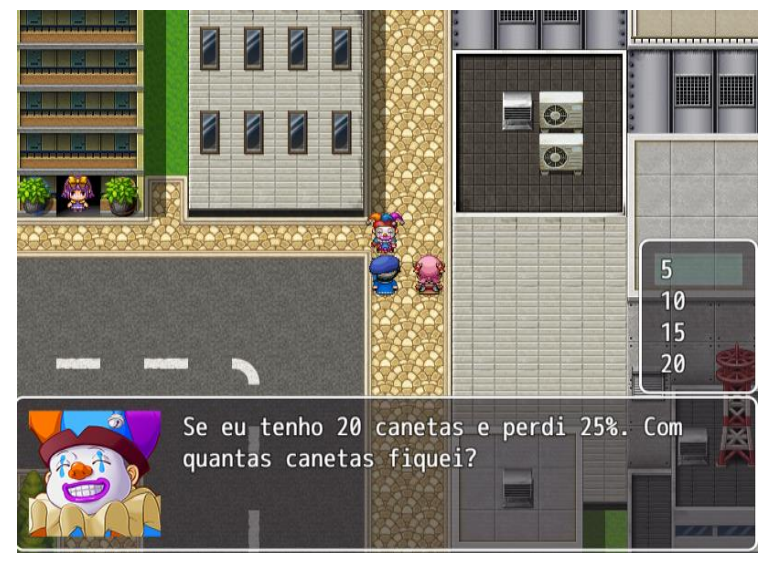

(Imagem 8: Fonte própria)

Durante as etapas o aluno se depara com o desafio de resolver as questões trazidas pelos personagens e atingir a maior pontuação possível. As fases poderão ocorrer na rua, na escola, ou até mesmo na casa do aluno. Se o aluno atingir uma pontuação alta, significa que ele conseguiu resolver uma grande quantidade de questões durante o jogo. Além disso existem baús com tesouros, animais e até professores que podem ajudar o aluno com dicas. Observe as imagens a seguir.

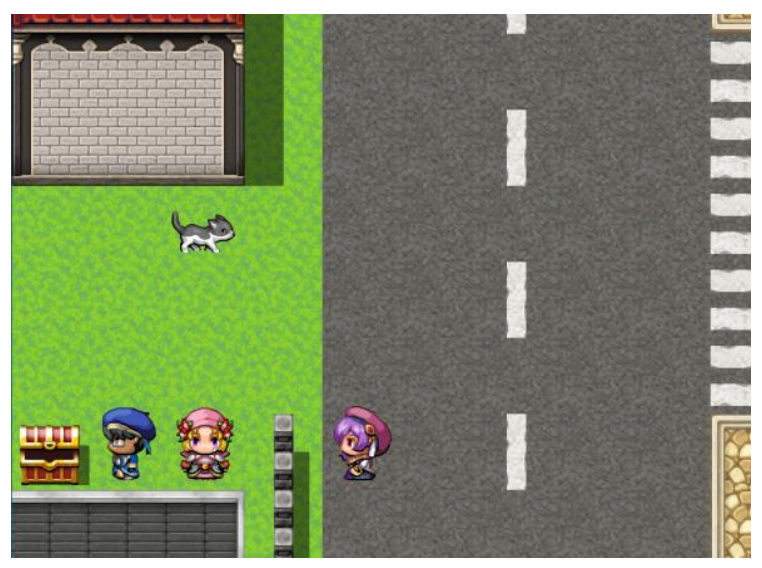

(Imagem 9: Fonte própria)

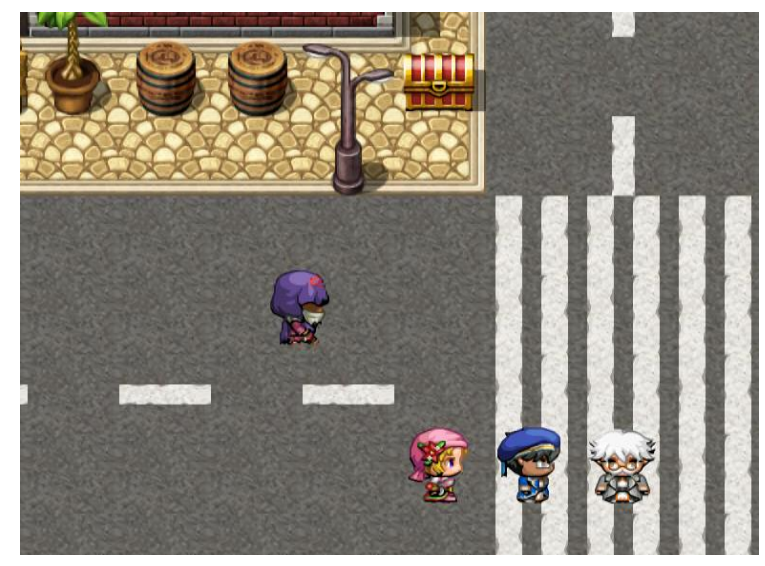

(Imagem 10: Fonte própria)

A programação que possui as questões é de fácil ajuste e alteração. O professor poderá fazer substituições das questões, alterar cenários e criar novas situações que possam atrair a atenção do aluno. Faz-se necessário conhecimentos de lógica de programação para manuseio e alteração. Logo, o professor deverá passar por uma capacitação e aprender a desenvolver jogos com esse tipo de logística. No entanto, essas ações e instrumentos despertam o interesse do aluno contemporâneo, pois, além de exercitar o conteúdo, o aluno se diverte.

\section{CONTEXTO DO ESTUDO E APLICAÇÃO}




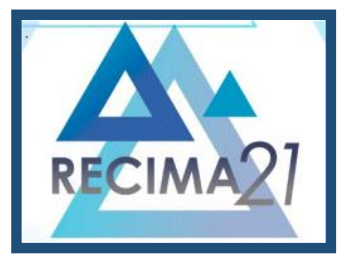

\section{RECIMA21 - REVISTA CIENTÍFICA MULTIDISCIPLINAR ISSN 2675-6218}

As observações foram realizadas em três turmas de sétimo ano, 1 no turno da manhã e 2 no turno da tarde. A turma $7^{\circ} \mathrm{A}$ tem 26 alunos, sendo que a maioria é de meninas. É uma turma bastante agitada, os alunos estão na faixa etária coerente com este ano escolar, com idade de 11 a 13 anos. Somente três alunos são repetentes. A turma $7^{\circ} \mathrm{B}$ tem 32 alunos, sendo que são 20 meninos e 12 meninas. É uma turma calma, os alunos estão na faixa etária coerente com este ano escolar, porém 2 alunos são repetentes. Já na turma $7^{\circ} \mathrm{C}$, são 29 alunos, sendo que a maioria é de meninos. É uma turma bastante barulhenta e gosta de conversar no momento da aula. Os alunos estão em faixa etária incoerentes com o ano escolar, existe alunos mais novos misturados com idade superior a faixa etária adequada. Possui três alunos repetentes.

Foram realizadas observações durante dois dias. O horário das turmas contempla três aulas da disciplina de Matemática, sendo que nas quintas-feiras são dois períodos consecutivos. $O$ período de observações totalizou 3 dias de aula incluindo o dia da avaliação. O quadro 1, a seguir, apresenta as datas, o número de aulas e as atividades realizadas pelo professor durante esse período:

\section{Quadro 1}

\begin{tabular}{|c|c|c|c|}
\hline Observações & Data & $\mathbf{N}^{\mathbf{0}}$ de aulas & Descrição da atividade \\
\hline $1^{\mathrm{a}}$ & $14 / 10$ & 1 & $\begin{array}{l}\text { Aula de revisão sobre porcentagem e Introdução ao } \\
\text { uso de jogos, explicação sobre atividade posterior. }\end{array}$ \\
\hline $2^{\mathrm{a}}$ & $17 / 10$ & 2 & Aplicação do jogo: "RPG - Uma nova abordagem “ \\
\hline $3^{\mathrm{a}}$ & $21 / 10$ & 1 & Avaliação e Resultados \\
\hline
\end{tabular}

Fonte própria

Na primeira aula observada, a professora aplicou uma aula sobre o conteúdo já estudado, trouxe questões e tentou sondar as dúvidas das turmas. Após o término da explicação informou aos alunos que na próxima aula aplicaria um jogo. Neste momento percebeu-se que grande parte da turma ficou entusiasmada com a notícia. Somente alguns alunos não vibraram como os demais. Primeiramente o professor mostrou o jogo denominado "RPG - Uma nova abordagem". Em seguida apresentou as regras, fazendo uma breve demonstração de como seria jogado. Os alunos formaram duplas e trios para jogar.

$\mathrm{Na}$ segunda aula, a professora inicia informando que o jogo será aplicado. Como seriam utilizados poucos computadores em sala, haveria uma espera em cada rodada, porém todos os alunos teriam a oportunidade de participar. Ao final, todos os alunos das turmas participaram do projeto. Outra observação importante foi constatar que os adversários também faziam os cálculos embora não fosse sua vez de jogar. Assim, quando necessário, podiam contestar os resultados obtidos nas jogadas e verificar se os resultados eram os mesmos. Quando não eram os mesmos, refaziam os cálculos. A situação evidencia o quanto é importante a interação entre os alunos no momento do jogo, pois eles discutem as maneiras de resolução, aprendendo uns com os outros, que mostram o quanto o jogo está sendo significativo e importante na construção do conhecimento. 


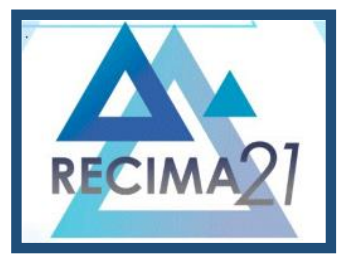

\section{RECIMA21 - REVISTA CIENTÍFICA MULTIDISCIPLINAR ISSN 2675-6218}

EXPERIMENTO COM JOGOS ELETRÔNICOS NO 7ํ ANO DO FUNDAMENTAL II DA ESCOLA DUQUE DE CAXIAS Leandro dos Santos Almeida, Annelise Maymone

Percebeu-se que os alunos estavam motivados e desafiados durante a atividade, chegando uma boa compreensão e a um bom raciocínio sobre porcentagem. $O$ jogo trouxe um interesse extra para 0 assunto.

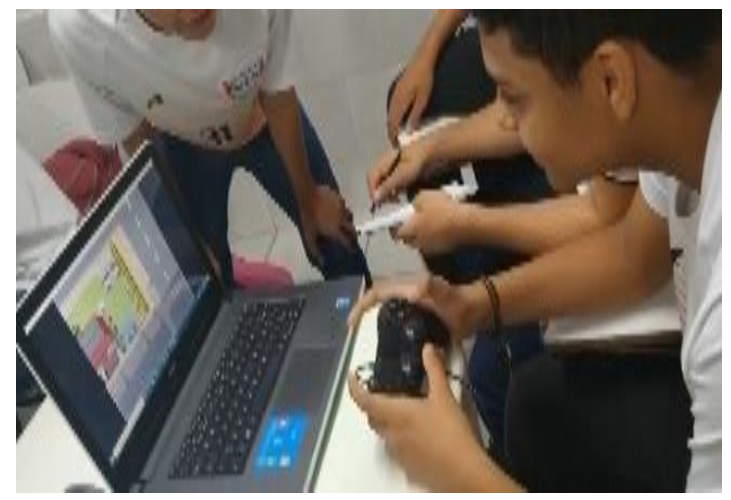

(Imagem 11: Fonte própria)

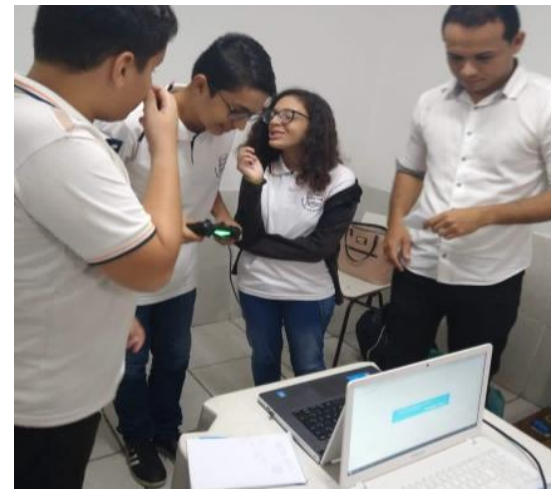

(Imagem 12: Fonte própria)

$\mathrm{Na}$ terceira aula observada, que foi posterior a aplicação do jogo "RPG - Uma nova abordagem", a professora introduziu uma avaliação abordando questões similares ao conteúdo aplicado no jogo. Os alunos mostraram-se bastante preparados na resolução dos exercícios. Quando surgiam dúvidas, o professor relembrava momentos dos jogos. Essa retomada permitiu aos alunos realizar uma retrospectiva do que haviam feito no jogo e utilizar conhecimento para a resolução de exercícios. Foram várias as vezes nessa aula que o professor utilizou o artifício de relembrar os momentos do jogo para auxiliar os alunos a resolver a atividade de avaliação. Os alunos interagiam com o professor e colegas durante a realização do exercício. Eles relembraram as jogadas e ficavam eufóricos. Ao final, a professora agradece a participação dos alunos e distribui as notas relacionadas ao jogo e a atividade proposta.

\section{RESULTADOS E DISCUSSÕES}

Através desse jogo, percebemos que a motivação e o interesse de cada aluno se desenvolveram. $\mathrm{O}$ ambiente se tornou favorável ao aprendizado. A ferramenta foi essencial para 0 entusiasmo e consequentemente para o estímulo do interesse em resolver as questões. Cada uma das ações dos alunos no jogo foi importante e essencial para o processo de assimilação do conteúdo. Enfatiza-se que os alunos das turmas foram receptivos ao projeto, participando ativamente da atividade. A curiosidade pelo novo, a cooperação entre os colegas para solucionar problemas ligados ao jogo aumentou o interesse pelo conteúdo abordado.

Segundo relatos da professora, os alunos atingiram um elevado nível no conteúdo e ótimas notas, além da mudança de comportamento, pois os alunos que antes eram desinteressados passaram a estudar com mais entusiasmo e também tiveram resultados satisfatórios. Os alunos não apresentam maiores dificuldades na Matemática contida no jogo e sim na interpretação das regras. Ainda conforme a professora, os estudantes expõem de maneira clara suas dúvidas e 


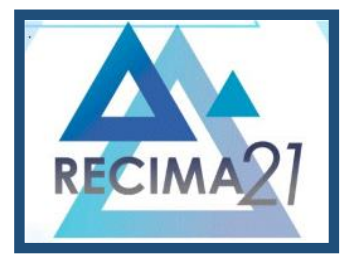

\section{RECIMA21 - REVISTA CIENTÍFICA MULTIDISCIPLINAR ISSN 2675-6218}

opiniões durante a aplicação do jogo, principalmente quanto a resolução das questões contidas no jogo. Durante a aplicação podemos destacar algumas dificuldades enfrentadas:

$>$ Barulho excessivo;

$>$ Falta de computadores e ambiente adequado;

> Quantidade de alunos deixa alguns alunos ociosos na espera;

> Nas turmas mais agitadas, falta o domínio do professor.

Ao término do ano letivo percebeu-se um avanço em relação ao aprendizado da turma. Porém a professora relata a importância de novos jogos ou novas ações para manter esse entusiasmo. Considerando os resultados obtidos, podemos concluir que é importante a utilização de recursos tecnológicos, porém faz-se necessário uma análise da sociedade seguida de capacitações para conseguir um elevado índice de aceitação e interações. Os jogos eletrônicos despertam interesse tanto dos alunos tímidos quanto dos alunos mais eufóricos, pois estão inseridos no dia a dia do mesmo.

\section{CONSIDERAÇÕES FINAIS}

O jogo utilizado na pesquisa foi de suma importância, através dele foi possível observar o entusiasmo aliado ao interesse dos alunos, buscando estratégias para resolução dos problemas.

O jogo apenas pelo jogo não serve para ensino e prática do exercício da matemática, porém, jogos com desafios fazem com que o aluno veja o problema matemático como um todo, assim, a aluno fica focado no problema, busca alternativas para chegar no seu objetivo, que quando está jogando, resume-se a ganhar, mas em sala de aula, resume-se a buscar as respostas para obter a vitória no jogo.

Trabalhar com jogos de maneira constante, não é tão simples, e nem garante a motivação, tampouco um bom desempenho dos alunos. Foi possível avaliar essa situação, pois a repetição tornará o momento previsível. O desafio age como motivador. Trabalhar de maneira alternada mostrou-se eficiente na concentração e desempenho para resolução de problemas.

Obter resultados satisfatórios com o uso de jogos eletrônicos requer planejamento e muita capacitação. A capacitação dos professores para esse tipo de ferramenta se faz indispensável, pois a situação atual de algumas escolas e até mesmo o despreparo docente são problemas que dificultam a abordagem tecnológica em muitos casos. A preparação dos futuros professores e a aceitação por parte dos professores que já atuam deve ser efetiva, pois, com os avanços tecnológicos, juntamente com a necessidade de atividades interativas, é necessário progredir também com as tecnologias educacionais e tentar acompanhar o uso dessas mídias trazendo para o ensino. Os alunos dessa faixa etária precisam de constante motivação para se manter concentrados e o uso desse tipo de jogo auxilia o professor.

Essas iniciativas sobre a capacitação devem partir inicialmente das instituições de ensino, mas principalmente do próprio professor, que deve ter consciência da necessidade de estar 


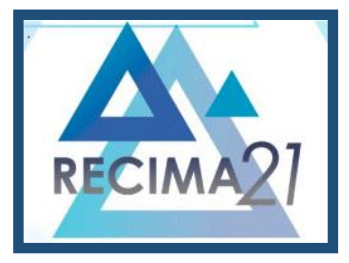

\section{RECIMA21 - REVISTA CIENTÍFICA MULTIDISCIPLINAR ISSN 2675-6218}

atualizado e que ensinar utilizando essa abordagem é algo trabalhoso e demanda mais tempo para preparação da aula.

Manter a estrutura da escola com ambientes e equipamentos em funcionamento, acompanhar as tendências digitais, são algo caro e, principalmente nas instituições públicas, mesmo naquelas com investimentos do setor privado, há de se compreender que nem sempre haverá à disposição opções de ponta, sendo assim é responsabilidade do professor aproveitar ao máximo tudo o que está à sua disposição. No que tange as dificuldades encontradas durante a pesquisa, podemos citar a falta de infraestrutura da escola por não dispor de equipamentos suficientes para que todos alunos pudessem participar. Grupos de 3 alunos ocupavam o mesmo equipamento, o que muitas vezes tirava a concentração daqueles que não estavam envolvidos no jogo e tinham que esperar sua vez.

O uso da tecnologia para ensino da matemática existe, porém está em permanente evolução. Podemos concluir que, utilizá-las aliadas a um planejamento adequado traz bons resultados na área da matemática, pois atua como motivador e tem como consequência a participação dos alunos, proporcionando uma maior concentração e melhor compreensão dos conceitos.

Percebeu-se que há a possibilidade de aprofundamento sobre o tema, pois, a cada dia novas tecnologias surgem, e muitas destas poderão ser utilizadas como facilitadores no processo de ensino e aprendizagem. O professor que utiliza jogos eletrônicos possui um imenso potencial e versatilidade, de forma a garantir cada vez mais um ensino de qualidade ao aluno contemporâneo.

\section{REFERÊNCIAS}

BECKER, H. J. How are teachers using computers in instruction? California: University of Irvine, 2001.

BRASIL. Secretaria de Educação Fundamental. Parâmetros curriculares nacionais: Introdução aos parâmetros curriculares nacionais. Brasília: MEC/SEE, 1997.

D'AMBROSIO, U. Da realidade à Ação: reflexões sobre educação e matemática. Campinas-SP: Summus/UNICAMP, 1986.

DOMINGUES, J. E. Lousa e giz: você aproveita bem essa tecnologia? Blog: Ensinar História, 2015. Disponível em: http://www.ensinarhistoriajoelza.com.br/lousa-e-giz-voce-aproveita-bem-essatecnologial. Acesso em: 04 set. 2020.

FIORNTINI, Dario; MIORIN, Maria Ângela. Uma reflexão sobre o uso de materiais concretos e jogos no Ensino da Matemática. Boletn SBEM-SP, Ano 4, n. 7, 1990.

GRANDO, R. C. A. O Conhecimento Matemático e o Uso dos Jogos na Sala de Aula. Campinas SP, 2000. Tese (Doutorado) - Faculdade de Educação UNICAMP, Campinas, 2000.

PAPERT, S. Computadores e conhecimento: repensando a educação. Campinas: Unicamp, 1993. VALENTE, J. A.; CANHETTE, C. C. Lego-logo: explorando o conceito de design. In.: VALENTE, J. A. (Org). Computadores e Conhecimento: Repensando a Educação. Campinas: Unicamp, 1993. 


\section{RECIMA21 - REVISTA CIENTÍFICA MULTIDISCIPLINAR ISSN 2675-6218}

EXPERIMENTO COM JOGOS ELETRÔNICOS NO 7을 ANO DO FUNDAMENTAL II DA ESCOLA DUQUE DE CAXIAS Leandro dos Santos Almeida, Annelise Maymone

VERGNAUD, G. El niño, las matemáticas y la realidade: problemas de la enseãnza de las matemáticas em la escuela primara. México: Trillas, 1991.

\section{ANEXO I}

\section{COLÉGIO DUQUE DE CAXIAS}

\section{LISTA DE EXERCÍCIOS 2 \\ Revisão - Porcentagem}

1. Calcule:

a) $30 \%$ de 2.400

b) $15 \%$ de 400

c) $15 \%$ de $40 \%$

d) $100 \%$ de 100

2. Se eu tenho 20 canetas e perdi $25 \%$. Com quantas canetas fiquei?

3. Um livro custa 100 reais, se for comprado a prazo, sai por 120 reais em 3 parcelas de $\mathbf{4 0}$ reais. Comprando à vista você tem $15 \%$ de desconto, quais são os valores do pagamento à vista e a porcentagem de acréscimo a prazo?

4. Um produto tem preço de 250 reais à vista. A prazo, em 5 parcelas mensais iguais, seu preço sofre acréscimo de $16 \%$. Qual é o valor de cada parcela?

5. Uma mercadoria é vendida na seguinte condição de pagamento: $\mathbf{2 0} \%$ de entrada e o restante em 5 prestações iguais de $\mathbf{R} \$ \mathbf{3 4 , 0 0}$. À vista concede-se desconto de $4 \%$. Qual é seu preço à vista?
6. (OBMEP - 06) Um trabalho de Matemática tem $\mathbf{3 0}$ questões de Aritmética e $\mathbf{5 0}$ de Geometria. Júlia acertou $\mathbf{7 0 \%}$ das questões de Aritmética e $\mathbf{8 0} \%$ do total de questões. Qual o percentual das questões de Geometria que ela acertou?

7. Numa mistura de $\mathbf{8 0} \mathbf{~ k g}$ de areia e cimento, $20 \%$ é cimento. Se acrescentarmos mais $20 \mathbf{~ k g}$ de cimento, qual será a sua porcentagem na nova mistura?

8. Na minha cidade, foi feita uma pesquisa sobre o meio de transporte utilizado pelos alunos para chegarem à escola. Responderam à essa pergunta 2000 alunos. $42 \%$ responderam que vão de carro, $25 \%$ responderam que vão de moto, e o restante de ônibus. Calcule todas as porcentagens possiveis.

9. Ao comprar um produto que custava RS $1.500,00$ obtive um desconto de $12 \%$. Por quanto acabei pagando o produto? Qual o valor do desconto obtido? 